\title{
Inflation Targeting in the Context of IMF-Supported Adjustment Programs
}

\author{
MARIO I. BLEJ ER, ALFREDO M. LEONE, PAU RABANAL, \\ and GERD SCHWARTZ*
}

This paper argues that the IMF's traditional monetary conditionality-a ceiling on net domestic assets of the central bank and a floor on its net international reservesshould be adapted in IMF-supported adjustment programs with countries that have a framework of explicit inflation targets for the implementation of monetary policy. This adaptation should aim at enhancing correspondence and consistency between the monetary objectives of the central bank and the targets established under the IMF-supported adjustment program, as well as between the different instruments used to achieve the policy objectives and targets. The paper reviews various general options in this regard, and, using the case of Brazil as an example, demonstrates how these options may be implemented in practice. [JEL E52, E31, E17]

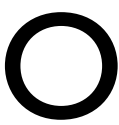

ver the past decade, the staff of the IMF has frequently been engaged in assessing the functioning and effectiveness of inflation targeting in IMF member countries that adopted this scheme as their monetary policy framework. As inflation targets were first embraced by various industrialized economies, however, this involvement was restricted to the IMF's surveillance functionthat is, it was part of the macroeconomic analyses performed during the regular

\footnotetext{
*When this paper was written, Mr. Blejer was a Senior Advisor in the IMF's Asia and Pacific Department, and Mr. Rabanal was a summer intern in the IMF's Western Hemisphere Department; both have since left the IMF. Mr. Schwartz was a Deputy Division Chief in the IMF's Western Hemisphere Department, and is now with the IMF's Fiscal Affairs Department. Mr. Leone continues to work as Assistant Director in the IMF's Monetary and Exchange Affairs Department. Earlier versions of this paper were presented at the conferences on "One Year of Inflation Targeting," in Rio de Janeiro (July 10-11, 2000), and "Ten Years of Inflation Targeting: Design, Performance, Challenges," in Santiago, Chile (November 30-December 1, 2000). We gratefully acknowledge the helpful comments and suggestions from Teresa Ter-Minassian, Marianne Schulze-Ghattas, Sandy Mackenzie, two anonymous referees, and the conference participants.
} 
annual consultations between the IMF and its member countries and not associated with IMF lending operations.

More recently, however, a number of emerging market economies have abandoned their fixed exchange rate regimes and moved toward a flexible exchange rate system with an explicit inflation targeting framework for monetary policy. In this context, it became increasingly likely that the IMF would face a situation in which it would be called upon to provide financial assistance-and therefore agree on a financial program - with a country that is using, or has decided to adopt, explicit inflation targets as the key component of its monetary policy framework. Indeed, shortly after adopting a floating exchange rate regime in mid-January 1999, the Brazilian authorities announced their intention to put in place a formal inflation targeting framework and, in the months that followed, the framework was implemented in the context of the ongoing IMF-supported adjustment program.

These developments posed particular analytical and practical challenges in terms of the operational procedures of the IMF in its financial relations with its member countries. The challenge resulted from the need to reconcile the inflation targeting framework with the conceptual and practical aspects of conditionality. Conditionality is the device utilized by the IMF in its financial programs, to establish safeguards that would help to maintain a country's external viability and ensure that its resources are only used temporarily. This, in turn, implies the adoption of so-called performance criteria - that is, formal quantitative targets on a defined number of variables, agreed between the member country and the IMF. The evolution of these variables is subject to verification, and fulfillment of these criteria is the condition for a disbursement to take place. In the monetary policy area, performance criteria in IMF-supported adjustment programs (henceforth IMF programs) have traditionally been set in terms of specific quantitative limits on the evolution of certain monetary variables. Typically, a floor is set for the level of net international reserves (NIR) and a ceiling is established on the net domestic assets (NDA) of the central bank.

At first sight, therefore, it would appear that the inflation targeting framework, by the very nature of its operating procedures, may not be compatible with the traditional quantitative monetary conditionality framework usually embodied in IMF programs. This is so because the actual implementation of inflation targeting is largely based on the premise that an independent central bank can use, at its own discretion, its various policy instruments, in the proportions considered appropriate in each particular circumstance, to ensure the attainment of its inflation goal. This seems to clash with a scheme that sets explicit and somewhat rigorous quantitative objectives for key monetary variables.

In these circumstances, and considering that it is the prerogative of each member country to adopt a monetary policy framework of its choice, the IMF faced the question of whether and how to adapt monetary conditionality to the specific features of monetary policy under inflation targeting. In general, it was concluded that, in principle, inflation targeting could be accommodated within the traditional structure of monetary conditionality in IMF programs, given that this conditionality focuses primarily on a program's balance of payments objective. At the same time, it was also recognized that it may be desirable to modify and 
supplement traditional monetary conditionality by introducing features that reflect the specific functioning of the inflation targeting framework. ${ }^{1}$

A main objective of this paper is, therefore, to consider the issues that arise from the adoption of inflation targeting in the context of the conditionality embodied in IMF programs, and to discuss a number of options for adapting the monetary conditionality of the programs to these particular cases. The next section briefly reviews in more detail the role of monetary conditionality in IMF programs.

\section{IMF Programs: The Role of Conditionality}

In IMF programs, conditionality refers to the linkage between the achievement of a set of policy objectives and the continuous access to IMF resources. ${ }^{2}$ The policy objectives are agreed between the IMF and the authorities of the member country, and, while the specific objectives vary from country to country, attaining a viable balance of payments position is the sine qua non target in every program. In this sense, conditionality has a double objective: it helps countries to maintain or regain financial discipline, and it provides a safeguard for the IMF's financial resources - that is, it helps ensure that the temporary financial support provided by the IMF can be repaid over a reasonably short period of time. The specification of the policy objectives and calibration of the quantitative targets should ensure that the need for financing is only temporary and that the borrowed funds will be repaid. Put another way, conditionality provides a yardstick for evaluating whether the policies that are being carried out are moving the country toward the achievement of the main policy objectives, in particular a sustainable external balance. By doing so, conditionality also ensures the temporary use of Fund resources. ${ }^{3}$

The effective implementation of conditionality does not involve day-to-day monitoring of a country's macroeconomic policies but requires a mechanism for assessing whether policies are on track for achieving their stated goals, or whether they need to be adjusted in response to unanticipated shocks, changes in economic relationships, or other new information. The monitoring mechanism in IMF programs consists of a set of explicit criteria-particularly performance criteria, but also indicative targets and structural benchmarks-that should be met if a country wishes to make further drawings under the program. These performance criteria typically refer to key macroeconomic variables-fiscal and monetary policy outcomes, including fiscal balances (for example, overall or primary

${ }^{1}$ A number of internal documents were prepared and discussed within the IMF to clarify the various aspects of this approach. Some of the considerations and arguments raised in these discussions are reflected in various parts of this paper.

2The word "conditionality" does not appear in the IMF's Articles of Agreement, and the concept evolved in stages. For a discussion of the legal aspects of the development of IMF conditionality, see Gold (1979). Guitián (1981) discusses the evolution of conditionality from an economic point of view.

${ }^{3}$ Analogies could be drawn between IMF lending to countries and central bank lending to troubled financial institutions, as both are ultimately aimed at maintaining or regaining financial stability and supporting economic growth. In both cases, specific contractual arrangements (such as conditionality) are intended to help, among others, to contain moral hazard (that is, the borrower's incentive to take on more risk after obtaining financial support), and to safeguard an orderly repayment of the borrowed resources. See Goodfriend and Lacker (1999) for a discussion related to central bank lending. 
balances), indebtedness (for example, public sector debt, public external debt, and its short-term component), and monetary variables, such as NIR and NDA ${ }^{4}$ - that indicate whether macroeconomic policies are on track. Also, IMF programs may include indicators related to certain structural reform measures (for example, structural benchmarks on specific reforms to be implemented). While performance criteria permit a backward-looking assessment of policies, periodic program reviews, which are often carried out quarterly, provide for a forward-looking overall assessment of the program vis-à-vis the government's stated macroeconomic policy objectives.

Quantitative macroeconomic performance criteria in IMF programs do not rely on a specific macroeconomic model. They do, however, make use of various balance-sheet identities that link monetary and fiscal variables with the balance of payments to ensure that the program is internally consistent. In general, these performance criteria may best be thought of as signaling devices that flag a possible need for corrective action in case of deviations.

\section{Monetary Conditionality: The Traditional Approach and Its Implications for Inflation Targeting}

Monetary policy conditionality has been at the core of IMF program conditionality. As mentioned above, it has traditionally relied on two performance criteria: a ceiling on a central bank's NDA and a floor on its NIR. ${ }^{5}$ Rooted in concepts that arise from the so-called "monetary approach to the balance of payments," and originally applied mostly in the context of fixed exchange rates, where the balance of payments has to adjust to monetary disequilibria, this methodology has come to be used under different monetary policy frameworks. Its primary focus has always been to ensure that a program maintains or leads to external viability rather than to impose tight control over inflation. In this context, performance criteria that set a floor on NIR are designed to indicate whether a program is likely to achieve its external objective. On the other hand, the ceiling on NDA could be seen as an additional protection, since it seeks to ensure that the external objective is not jeopardized by excessive credit expansion or by sterilized intervention (that is, by compensating unprogrammed NIR losses through additional credit creation), which is particularly relevant under fixed exchange rate regimes. In general, this framework is rooted in the assumption that the demand for base money matters from a macroeconomic perspective, and that it is stable and predictable.

In practice, the expected functioning of the NIR/NDA performance criteria would be as follows. An anticipated, or baseline, path for NIR is projected and a floor for NIR is set at or somewhat below the baseline. At the same time, the NDA ceiling is set at a level that, in conjunction with the projected evolution of velocity, is consistent with the NIR baseline. If a country's actual NIR were to start falling

${ }^{4}$ Usually, NDA are defined to equal base money minus NIR.

${ }^{5}$ While these have been by far the most common variables used in the design of monetary conditionality, in many countries other monetary aggregates have been targeted, and, in some cases, subceilings for specific types of domestic assets were also implemented. 
toward the agreed NIR floor-maybe because of a sudden external shock-monetary policy would need to be tightened, usually through open market operations, to help stop further NIR losses. In contrast, as long as actual NIR remain close to their baseline, the ceiling on NDA effectively limits base money expansion, thereby preventing monetary policies from putting additional pressure on the external balance and fueling inflation. More generally, the NIR/NDA mechanism sets off warning signals that there is a need for policy action, usually to tighten monetary policies, when NIR fall too low or when there is an oversterilization of unprogrammed sales of NIR. By providing a simple automatic signal, the framework helps country authorities to bring about needed policy actions that it may be reluctant to carry out otherwise. Still, the NIR/NDA framework does not prevent larger-than-programmed NIR increases from fueling monetary expansion and, thus, potentially inflation. A general overview is provided in Table 1.

Different views may reasonably be held on the appropriateness of the traditional NIR/NDA framework under an inflation targeting regime. As for the NIR floors, for example, it could be argued that they no longer have a place in this context, given that inflation targeting goes hand-in-hand with floating exchange rates. ${ }^{6}$ However, while under inflation targeting the central bank would not be expected to use its NIR to stabilize the exchange rate per se, it may react to movements of the exchange rate to the extent that they are perceived to threaten the inflation target. As most floats are not pure floats, trade-offs between domestic objectives (that is, inflation) and external objectives (that is, external viability) may be unavoidable, at least conceptually. Thus, even under flexible exchange rates, retaining an NIR floor simply reflects the fact that one important aspect of an IMF program is to safeguard external viability, independent of the monetary policy framework.

In contrast, it could be argued that retaining a ceiling on NDA under inflation targeting could help prevent large departures from the inflation objective-that is, NDA ceilings could reinforce a country's commitment to a flexible exchange rate policy and limit sterilized foreign exchange market intervention and base money expansion when the external position is weak. ${ }^{7}$ This view implicitly assumes that there exists a stable relationship between NDA and inflation. In most inflation targeting countries, however, it has been difficult to find robust empirical evidence on the existence of such a relationship. Hence, NDA ceilings would neither provide adequate guidance to monetary policies aimed at meeting an inflation target, nor would they provide a helpful trigger or focus for discussions on the monetary policy stance in an IMF program context, given the strong likelihood of false alarms.

Similarly, it could also be argued that maintaining NDA ceilings in an inflation targeting context could help to strengthen the credibility of the inflation target

${ }^{6}$ Note though, that some inflation targeting countries maintain managed floats, sometimes even with exchange rate bands. This could potentially lead to conflicts between the policy objectives regarding the inflation target and the exchange rate.

${ }^{7}$ Such safeguards would seem especially relevant when country authorities view exchange market pressures as essentially short lived. 
Mario I. Blejer, Alfredo M. Leone, Pau Rabanal, and Gerd Schwartz

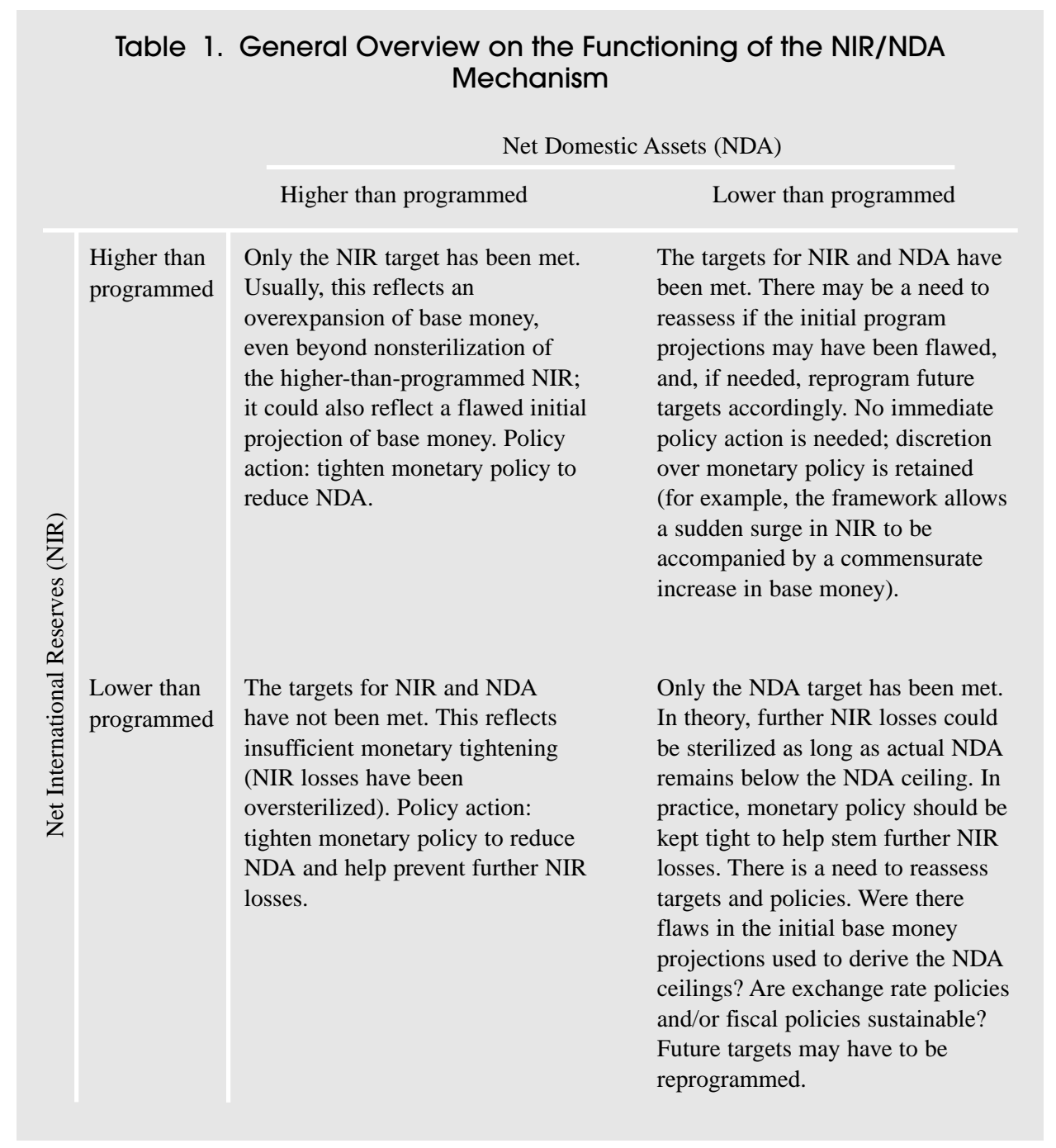

by protecting the central bank from pressures to monetize fiscal deficits. IMF programs always contain fiscal conditionality, however, which is the more direct (and therefore better suited) instrument to help ensure fiscal sustainability-that is, to ensure that there is no "fiscal dominance," which is commonly considered a precondition for successful implementation of inflation targeting. ${ }^{8}$

More generally, with a central bank that targets inflation and an IMF program that focuses on the quantity-based framework of NDA ceilings, there would not necessarily be a clear correspondence between the monetary objectives underlying the program and the relevant instruments to achieve the inflation targets. In addition, communication with the markets and the public regarding the stance of

\footnotetext{
${ }^{8}$ For an analysis of strategic and operational issues relevant to the implementation of inflation targeting frameworks, see Blejer and others (2000).
} 
monetary policy could easily become confusing. This is important because inflation targeting, by its very nature, relies critically on transparency of the central bank's policy actions. Since, as already pointed out, inflation is usually not primarily a function of NDA or its components, it is unlikely to respond predictably or immediately to changes in NDA or base money.

As a result, retaining an NDA ceiling-or any additional monetary target (such as exchange rate bands or caps on money growth) - could easily result in conflicting signals and therefore confuse markets when there is, in fact, no need to change monetary policy from the point of view of the inflation objective. ${ }^{9}$ For example, one may easily conceive a situation where actual NDA exceeds the NDA ceiling, while both actual and projected inflation are still within their target. Should monetary policy be tightened in these circumstances, or should the NDA ceiling be revised upward? Since inflation is the target, an upward adjustment of the NDA ceiling seems to be the only appropriate course of action. Similarly, when actual NIR is running significantly above the NIR floor, while base money is close to the projected baseline, monetary policies could only be eased to the extent that the inflation objective is not jeopardized. In general, as shown in Table 2, when inflation is the overriding objective, having an NDA ceiling may be considered somewhat superfluous or, at least, a nonbinding constraint.

In light of these various considerations, current thinking-as will be discussed below in the context of the Brazilian program-would hold that NIR floors would continue to be needed to safeguard an IMF program's external objectives, but that NDA ceilings would not necessarily be the preferred choice for monetary conditionality.

\section{Options for Implementing and Strengthening Monetary Conditionality Under Inflation Targeting}

Inflation targets provide an anchor for inflation expectations. While important issues remain as to when and under what conditions inflation targeting would be preferred to an exchange-rate-based stabilization, an increasing number of countries have abandoned fixed exchange rates and moved toward formal inflation targeting. ${ }^{10}$ In light of the inconsistencies that may arise when applying traditional monetary conditionality under inflation targeting, it was felt that monetary conditionality should be modified to reflect more closely the main parameters of

\footnotetext{
${ }^{9}$ Also see, for example, Rudebusch and Svensson (2002) for a discussion of potential problems of "two-pillar" frameworks, where monetary policy is geared toward meeting both an inflation objective and another objective, such as money growth.

${ }^{10}$ As argued by Schaechter, Stone, and Zelmer (2000), the foundations for successful full-fledged inflation targeting are built on the following: a strong fiscal position and entrenched macroeconomic stability; a well-developed financial system; central bank instrument independence and a mandate to achieve price stability; a reasonably well understood transmission mechanism between monetary policy actions and inflation; a sound methodology for constructing inflation forecasts; and transparency of monetary policy to build accountability and credibility. However, largely it still remains to be seen to what extent the absence of any of these elements, including during the initial phases of an inflation targeting regime, may limit the ultimate success of inflation targeting.
} 
Table 2. Monetary Conditionality with NDA and Inflation Targets

\begin{tabular}{|c|c|c|c|}
\hline & & \multicolumn{2}{|c|}{ Inflation Target (IT) } \\
\hline & & Threatened & Not threatened \\
\hline \multirow{2}{*}{ 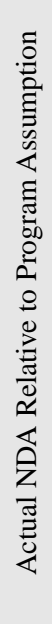 } & $\begin{array}{l}\text { Higher than } \\
\text { programmed }\end{array}$ & $\begin{array}{l}\text { NDA and IT give } \\
\text { the same signal: } \\
\text { tighten monetary } \\
\text { policy. }\end{array}$ & $\begin{array}{l}\text { NDA and IT give a } \\
\text { different signal: } \\
\text { NDA suggests } \\
\text { tightening; IT } \\
\text { suggests no } \\
\text { tightening is } \\
\text { needed. }\end{array}$ \\
\hline & $\begin{array}{l}\text { Lower than } \\
\text { programmed }\end{array}$ & $\begin{array}{l}\text { NDA and IT give } \\
\text { a different signal: } \\
\text { IT suggests } \\
\text { tightening; NDA } \\
\text { suggests no } \\
\text { tightening is } \\
\text { needed. }\end{array}$ & $\begin{array}{l}\text { NDA and IT give } \\
\text { the same signal: } \\
\text { no tightening of } \\
\text { monetary policy } \\
\text { is needed. }\end{array}$ \\
\hline
\end{tabular}

decision making under inflation targeting. Ideally, under inflation targeting monetary conditionality should be geared toward evaluating the monetary policy stance vis-à-vis the government's announced inflation target. This would require an extremely good understanding of all the elements involved, however, including, for example, the transmission channels and the precise parameters of monetary policy and the external environment.

Moreover, monetary conditionality should primarily apply to specific policy actions and policy instruments (for example, interest rates), since country authorities cannot commit to achieve a particular level of a variable over which they do not exercise some decisive degree of control (for example, interest rate spreads). It could be argued that, ideally, monetary conditionality should involve the various parameters of a policy reaction function-that is, the summary forward-looking rule governing the policy responses to projected deviations of inflation from the inflation target. Following this reasoning, a potential conditionality device for IMF programs under inflation targeting could consist of an operational rule for reacting to actual or expected deviations from the targeted inflation path. This rule should, again ideally, be a simple but robust reaction function that relates changes in an instrument (for example, interest rates) to deviations of inflation from its target. Note that this would be far more specific, and therefore restrictive in terms of the policy response, than the conditionality under the NIR/NDA mechanism, which simply sets off a warning signal that policies need to be tightened without specifying by how 
much. In practice, it would be impossible to specify the exact timing and size of the response parameter-that is, to determine in advance by how much and when interest rates should be adjusted when projected inflation deviates from its target by a given amount. Also, while a very specific reaction function may work in one program, this may not be sufficiently general and flexible to accommodate different approaches to inflation targeting, and therefore, given the IMF's commitment to provide equality of treatment to all its members, this could possibly entail some problems of cross-country comparability.

Despite these limitations, and while it may neither be possible nor even desirable to specify in advance a very precise policy reaction function, at least not for the purpose of monetary conditionality in an IMF program context, it would still seem useful to have a simple forward-looking mechanism for gauging the monetary policy stance vis-à-vis the inflation target. In this context, it could be useful to consider simple monetary policy rules, such as a Taylor rule for the short-term interest rate or a McCallum rule for the monetary base. In general, such rules are only of limited use in guiding policy decisions, because it could easily be counterproductive for the monetary authorities to commit to a simple instrument rule in pursuing their ultimate target, the inflation outcome. ${ }^{11}$ It is generally acknowledged, though, that simple policy rules may serve as rough benchmarks for good monetary policy, ${ }^{12}$ which makes them interesting as a potential conditionality device in an IMF program context. In other words, simple policy rules can serve as a starting point for thinking about whether the monetary policy stance is appropriate, but mechanically applying them would not be recommendable for a policymaker facing real-time decisions.

In general, monetary policy rules are quite flexible to encompass a range of relevant information. A simple Taylor rule, ${ }^{13}$ for example, can be expressed as $r=r^{*}+\alpha\left(Y-Y^{*}\right)+\beta\left(\pi-\pi^{*}\right)$, where $r$ is the nominal short-term interest rate, $r^{*}$ is an estimated nominal equilibrium interest rate that is consistent with the target inflation rate (that is, $r^{*}=\bar{r}+\pi^{*}$ with $\bar{r}$ being the equilibrium real interest rate and $\pi^{*}$ being the relevant inflation target); $Y$ is output and $Y^{*}$ is capacity output; $\pi$ is inflation (either actual or projected); and $\alpha$ and $\beta$ are coefficients, with $\alpha \geq 0$ (and typically between 0 and 0.5 , depending on the degree to which the output gap figures in the central bank's reaction function) and $\beta>0$ (and typically between 1.5 and 2 , so that the nominal short-term interest rate moves significantly in response to deviations of inflation from the inflation target). In an open economy, one could add a number of other variables in this rule-for example, the external current account or the foreign output gap. Also, the rule could include other variables that reflect conditions in the domestic economy, such as the government's budget balance or other fiscal variables. In fact, within this context it is also feasible to include in a Taylor rule different inflation measures, like in the following rule: $r=r^{*}+\alpha\left(\gamma\left(\pi^{a}-\pi^{*}\right)+(1-\gamma)\left(\pi^{p}-\pi^{*}\right)\right)$, where $\pi^{a}$ is actual inflation and $\pi^{p}$ is projected inflation and $0<\gamma<1$.

\footnotetext{
${ }^{11}$ Also see Svensson (2002).

${ }^{12}$ See, for example, Svensson (2001) or Kozicki (1999) for an overview.

${ }^{13}$ See Taylor (1993) for the original formulation.
} 
Moreover, one could include competing inflation projections in a similar fashion. Hence, Taylor rules are very flexible and can be specified to encompass a number of country-specific considerations.

As a rough check on the monetary policy stance in an IMF program context, it would probably be important to specify monetary policy rules somewhat cautiously, and to reduce the likelihood of false alarms. For example, for a Taylor rule one could choose $\bar{r}$, the equilibrium real interest rate that underlies $r^{*}$, to be slightly lower than the best available estimate based on historical data; this would allow for some limited flexibility on interest rate policies. Alternatively, one could use a range of equilibrium interest rates to generate Taylor rule "bands" analogous to target bands for inflation.

However, given that a key element in a simple monetary policy rule is the parametric reaction to deviations between actual or projected inflation and the inflation target, an obvious weakness of such an approach is that it would not react to shocks to variables that are omitted from the rule-for example, a Taylor rule would only show a reaction to an external shock if that shock was, in one way or another, part of the rule. Also, simple linear policy rules, like the ones discussed here, would not be adequate for judging the stance of monetary policy in special circumstances, for instance when a country is just exiting from a period of high inflation.

Given the limitations, in an inflation targeting context, of both the traditional quantitative NDA ceilings and of simple monetary policy rules, and considering the difficulties that would exist in specifying and agreeing in advance on a detailed monetary policy reaction function, there appears to be an enhanced role for regular periodic policy reviews that would include a detailed assessment of monetary policy in the context of inflation targeting. In this regard, the IMF program would still need to specify an inflation path consistent with the official inflation targets. While official inflation targets tend to be annual, however, the program would establish more frequent, say quarterly, intermediate inflation targets. In the context of the regular IMF program reviews, current and projected inflation would be compared with the target path, and agreement on specific policy actions would be reached whenever the outlook suggested that inflation objectives were likely to be missed.

\section{Adapting Monetary Conditionality to Inflation Targeting in Brazil}

Brazil was the first inflation targeting country with an IMF program, and it took some time to tailor the program to the floating exchange rate regime with the nominal inflation target. In part, this reflected the need to take into account the institutional constraints that require similarity of treatment and, hence, a high degree of comparability of IMF programs across countries.

Initially, the program with Brazil relied on traditional monetary conditionality—an NIR floor and an NDA ceiling —although it introduced some interesting innovations as well. In general, as shown in Table 3, whereas the initial program in December 1998 - still under the fixed exchange rate regime-relied mainly on 
a strict NDA ceiling for conditionality in the monetary area, the NDA ceilings were made less binding after Brazil adopted the inflation targeting framework, and were completely phased out in June 2000 with the inflation targeting framework fully established. In contrast, while the initial program included an NIR floor that was intentionally fixed at a low (or nonbinding) level to allow the Central Bank of Brazil (BCB) to use part of its actual NIR to defend the fixed exchange rate, if needed, the NIR floor became the key instrument of conditionality in the first few reviews in 1999, in an environment where uncertainty concerning the new monetary policy framework (and with it the new nominal anchor for inflation expectations) was still considerably high. In July 1999, shortly after Brazil had formally established its inflation targeting framework, the NIR/NDA conditionality was supplemented with a general consultation mechanism on inflation targets. In November 1999, less than six months after the inflation targeting framework had been put in place, the IMF program incorporated a formal consultation mechanism on inflation to supplement the floor on NIR.

The progressive shift away from NDA ceilings following the adoption of the inflation targeting framework reflected the need to adapt the program to the changes in the monetary policy regime. The shift also reflected the growing realization of the fact that base money did not appear to play a significant role in the monetary transmission mechanism in Brazil. ${ }^{14}$ In particular, seasonalities, remonetization under the Real Plan, and the effects of tax changes have been quantitatively more important and statistically more significant determinants of the demand for base money than the traditional variables, income, or the interest rate. ${ }^{15}$ In fact, the demand for base money seemed not very sensitive to interest rates at all.

The formal consultation mechanism on inflation, introduced in the November 1999 review of the program, was based on the annual central inflation target and

\footnotetext{
${ }^{14}$ In general, main transmission channels of monetary policy are the exchange rate, wages, asset prices, and aggregate demand. In Brazil, and in light of the economic conditions that have prevailed since inflation targeting was adopted in mid-1999 (that is, the fairly high real interest rates, tight fiscal policies, relatively subdued aggregate demand, and negative real wage growth), the exchange rate would appear to have been the main actual channel of transmission to inflation. This would be consistent with recent findings that suggest that the unwinding of real exchange rate misalignments in the context of a depreciation has been the most important determinant of inflation in developing economies (Goldfajn and Werlang, 2000; for Brazil see also Schwartz, 1999). Of course, in a floating exchange rate regime, the exchange rate itself is not a policy variable. For a discussion of the transmission mechanism of monetary policy in Brazil, see Rabanal and Schwartz (2001a).

${ }^{15}$ To establish NDA ceilings, the demand for base money was estimated as the sum of its two parts: currency issued and reserves on demand deposits. Currency issued was modeled as a function of a linear trend (to capture the ongoing remonetization of the economy), various seasonal dummies (for example, for December, January, and February), and lagged dependent variables. Demand deposits were modeled as a function of seasonal dummies, dummies for tax effects (for example, changes in the tax on financial transactions (CPMF)), and the nominal interest rate. Reserves on demand deposits were derived by applying an effective reserve rate to the projected level of demand deposits. In the short term, these projections fared quite well, but larger deviations from the econometric estimates occurred when there were shifts in seasonalities (for example, carnival in March instead of February), or when special factors, like tax changes (for example, in the CPMF) or the Y2K "bug," did not have the anticipated effects.
} 


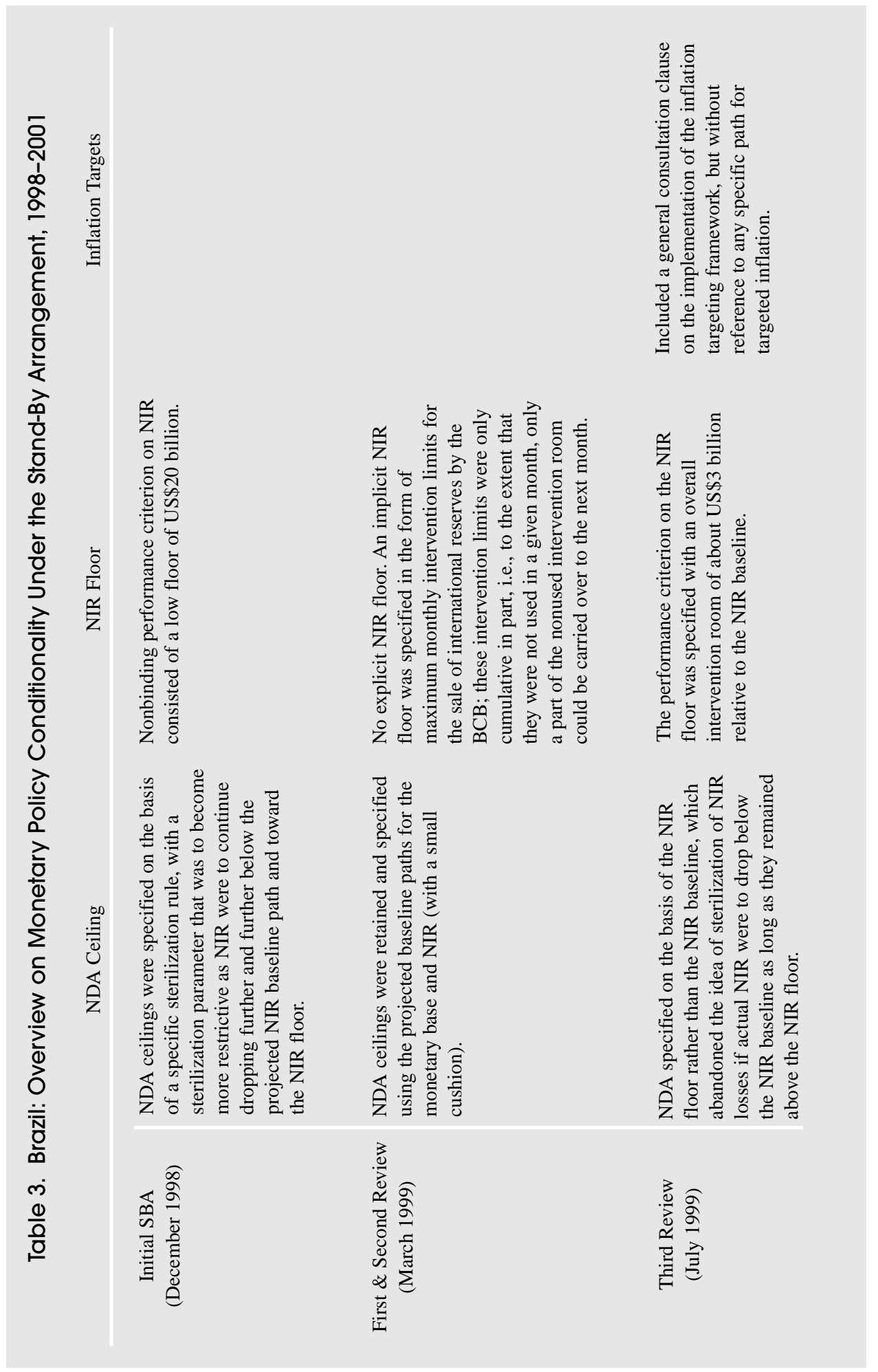




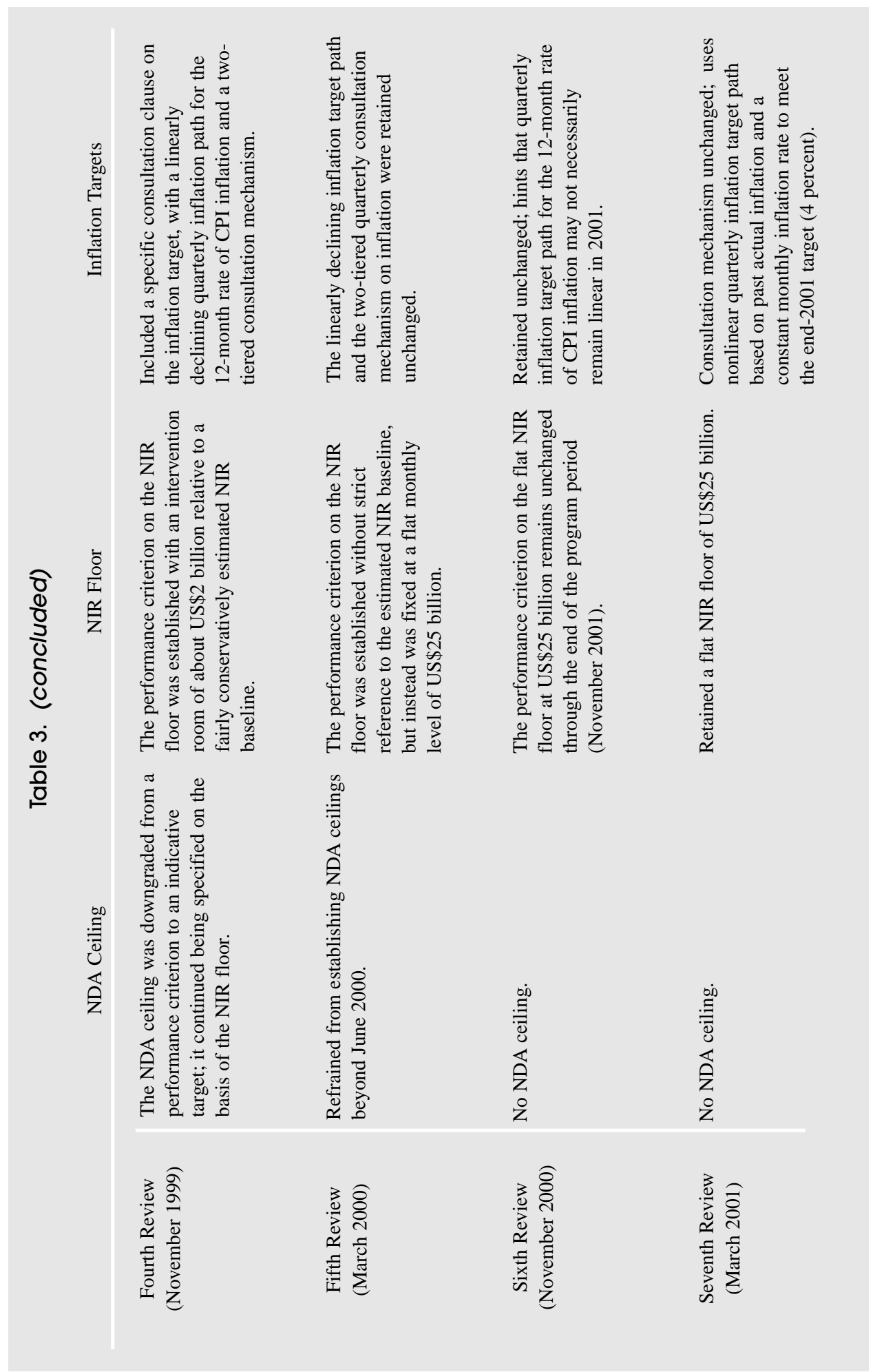


the tolerance bands that had been announced by the Brazilian government. ${ }^{16}$ Under the program, a simple linear quarterly path was established, where the central inflation target declined by 0.5 percentage points each quarter. ${ }^{17}$ Also, the program established a two-tier "consultation band" around the central target: an "outer band" with a width of $+/-2$ percentage points around the central target path, and an "inner band" with a width of $+/-1$ percentage points around the central target path. Accordingly, and this was the innovation in conditionality, the Brazilian authorities would informally consult with IMF staff on the appropriate policy response if the observed 12-month rate of IPCA (a consumer price index) inflation were to go outside the inner band; they would more formally consult with the IMF Executive Board on the appropriate policy response if the observed 12-month rate of inflation were to go outside the outer band.

How well did this mechanism work? Figure 1 shows Brazil's actual inflation performance in relation to the established consultation bands during 1999-01. In general, the BCB met its official inflation targets for both end-1999 and end-2000. The consultation mechanism on inflation with the IMF staff was triggered twice, first in September 2000, when the 12-month rate of consumer price (IPCA) inflation reached 7.8 percent, thereby exceeding the program's 7.5 percent ceiling of the inner band, and then again in June 2001, when the 12-month rate of IPCA inflation reached 7.4 percent, thereby exceeding the program's 6.9 percent ceiling of the inner band. The consultation mechanism with the IMF Executive Board did not have to be invoked, as deviations from the central target path remained within the $+/-2$ percentage-point spread.

The first consultation with IMF staff largely resulted from a temporary surge in monthly inflation rates in July and August 2000, due to unanticipated supply shocks that abated in September 2000; core inflation had already remained relatively more subdued throughout the third quarter of 2000. In line with expectations, and facilitated by the continued firm stance of monetary policy, the rate of inflation in consumer prices declined in the fourth quarter of 2000 to match the official 6 percent target by end-2000. The second consultation with staff largely resulted from the pass-through to domestic prices that reflected the significant weakening of the Brazilian real against the U.S. dollar during late 2000 and in the first half of 2001, in the context of the lingering crisis in Argentina. These events ultimately caused Brazil to enter into a new stand-by arrangement (SBA) with the IMF in late 2001, rather than letting the arrangement expire in December 2001.

While the consultation mechanism has been useful in drawing attention to events that could threaten achievement of the government's official inflation target, the mechanism itself, which relies exclusively on comparing actual inflation outcomes against a target path, can be criticized for being largely backward

\footnotetext{
${ }^{16}$ Specifically, the announced inflation target was 8 percent at end-1999, 6 percent at end-2000, and 4 percent at end-2001, each with a tolerance band of $+/-2$ percentage points around the central target.

${ }^{17} \mathrm{~A}$ linear path was chosen mainly for simplicity. Another simple option would have been to establish a path for the target 12-month inflation rate on the basis of inflation that has already happened, and then simply add to that one-quarter of the year-end inflation target. For example, at the beginning of 2000, the target for, say, June 2000 could have been established by adding to the already known inflation outcome for July-December 1999, one half of the year-end target for 2000.
} 
Figure 1. Brazil: 12-Month Rate of Consumer Price Inflation (IPCA) and IMF Program Consultation Bands on Inflation

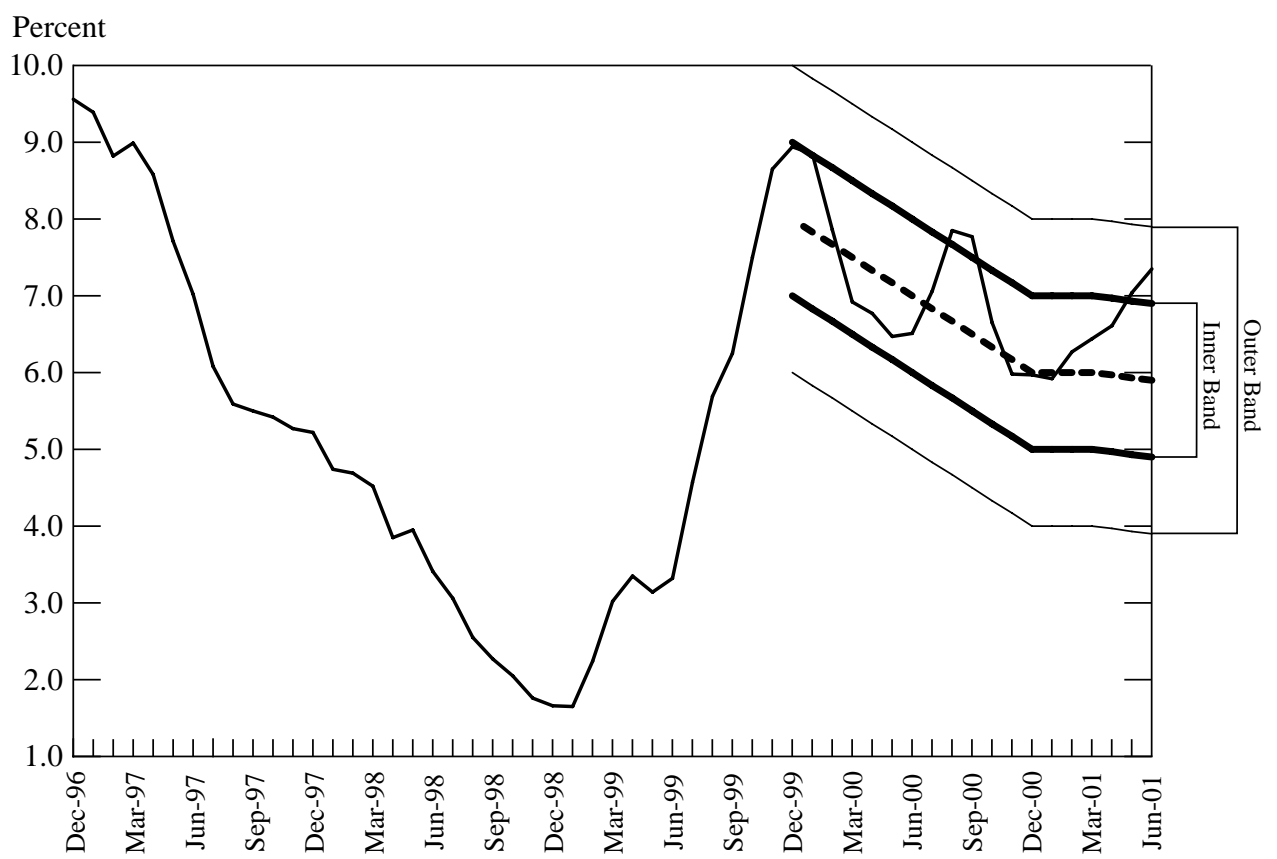

Sources: IGBE and IMF staff estimates.

looking. In the case of Brazil, it had become clear well ahead of time that the September 2000 and June 2001 ceilings for the inner band would in all likelihood be missed. More generally, the need for policy action would usually be expected to come well before the activation of the program's trigger mechanism for consultation. These considerations may argue in favor of using a more forward-looking monetary conditionality device.

\section{Actual Policies and Taylor Rules: An Application to Brazil}

Toward the background of this discussion, and mainly for illustrative purposes, this section explores the usefulness of some simple Taylor rules as an option for strengthening the monitoring of the monetary policy stance in the context of an IMF program in a country operating under an inflation targeting framework. The basic idea is simple: if it were possible to conclude that a simple monetary policy rule provides a rough indication of the appropriateness of a country's monetary policy stance vis-à-vis the inflation target, then it could usefully be employed as an automatic trigger mechanism for consultations in an IMF program context. To the extent that the monetary policy rule includes forward-looking elements (for example, inflation expectations), it could represent a more timely mechanism than the consultation mechanism that has been included in the program with Brazil. 
For purposes of illustration, we use, as an example, the experience of Brazil during its first 18 months under inflation targeting. Given the BCB's general success with inflation targeting, we ask whether a simple Taylor rule would have provided a useful assessment of the monetary policy stance.

Figures 2 and 3 show the actual interest rate, the annualized overnight interest rate ("SELIC rate"), plotted against two alternative Taylor rules, with different values for the $\alpha$ and $\beta$ parameters. In the first alternative, $\alpha$, the parameter on the output gap, equals 0.5 , and $\beta$, the parameter on the deviation of actual inflation from target, equals 1.5. The second version is an "aggressive" Taylor rule, where only the deviation of inflation from target features in the rule $(\beta=2)$. Figure 3 differs from Figure 2 in that it includes an interest smoothing parameter $\rho$, which is set equal to $0.6 .^{18}$ Initially, in both Figures 2 and 3 the actual 12-month rate of inflation is used in the simple Taylor rule. The Taylor "bands" shown in these two figures are generated by different assumptions on the equilibrium real interest rate $\bar{r}$, ranging from 10 percent to 12 percent. For the purpose of the exercise, the potential output growth rate was assumed to be 4.5 percent; a lower potential growth rate (of, say, 4.0 percent) would have resulted in a smaller output gap, and therefore kept the Taylor band at a slightly higher level.

In both Figures 2 and 3 we can clearly distinguish several, fairly short, subperiods during July 1999-June 2001. In general, the BCB followed a fairly cautious approach, where its main policy instrument, the SELIC rate, was kept broadly at or slightly above the level suggested by the Taylor bands, maybe with the possible exception of late-1999/early-2000. Starting in mid-2000, however, following a period of inflation surprises related to increased external uncertainties and a negative agricultural supply shock, and as the BCB continued to reduce the SELIC rate in late 2000, the Taylor bands would probably have suggested keeping the SELIC rate at the slightly higher level than what was actually done by the BCB, particularly when growth considerations are ignored $(\alpha=0)$. In light of the likely inflation outcome for 2001, with the year-end inflation target of 4 percent (with a $+/-2$ percent tolerance interval) likely to be missed slightly, the Taylor rule would have helped to trigger discussions early on.

Initially, during July-September 1999, the BCB kept the SELIC rate at a higher level than what a simple Taylor rule would have suggested on the basis of the relatively low pass-through that had occurred in the first couple of months after the Real was left to float. When the inflation targeting framework was launched in July 1999, inflation was at a very moderate level but expected to rise. Concerned about an increasing pass-through (given the existing transmission lags), and having to establish its reputation, the BCB initially adopted a tougher policy stance than what would have been suggested by a simple Taylor rule without expectational variables. In addition, caution during this early period also seemed warranted due to a deterioration in inflation expectation in early July 1999 that was brought about by an adjustment of government-managed prices. ${ }^{19}$

\footnotetext{
${ }^{18}$ The interest smoothing parameter introduces some inertia into the Taylor rule by mitigating the extent to which the central bank reacts to new information. See the Appendix for further detail on the exercises that were carried out.

${ }^{19}$ Also see Fachada (2001) for details.
} 
Figure 2. Brazil: Taylor Rules with Current Inflation

2a. The SELIC and a Simple Taylor Rule $(a=0.5, b=1.5)$

No Interest Rate Smoothing

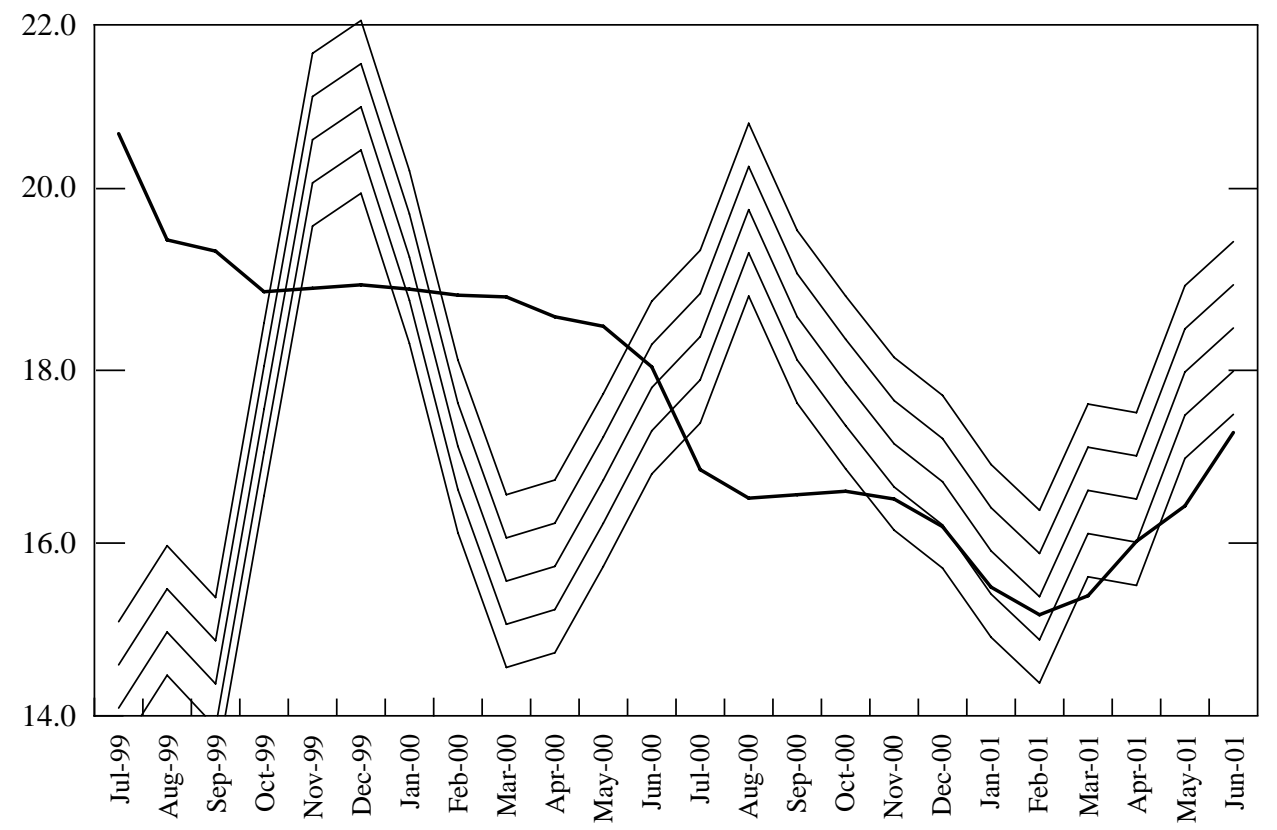

2b. The SELIC and a Simple Taylor Rule $(\mathrm{a}=0, \mathrm{~b}=2)$

No Interest Rate Smoothing

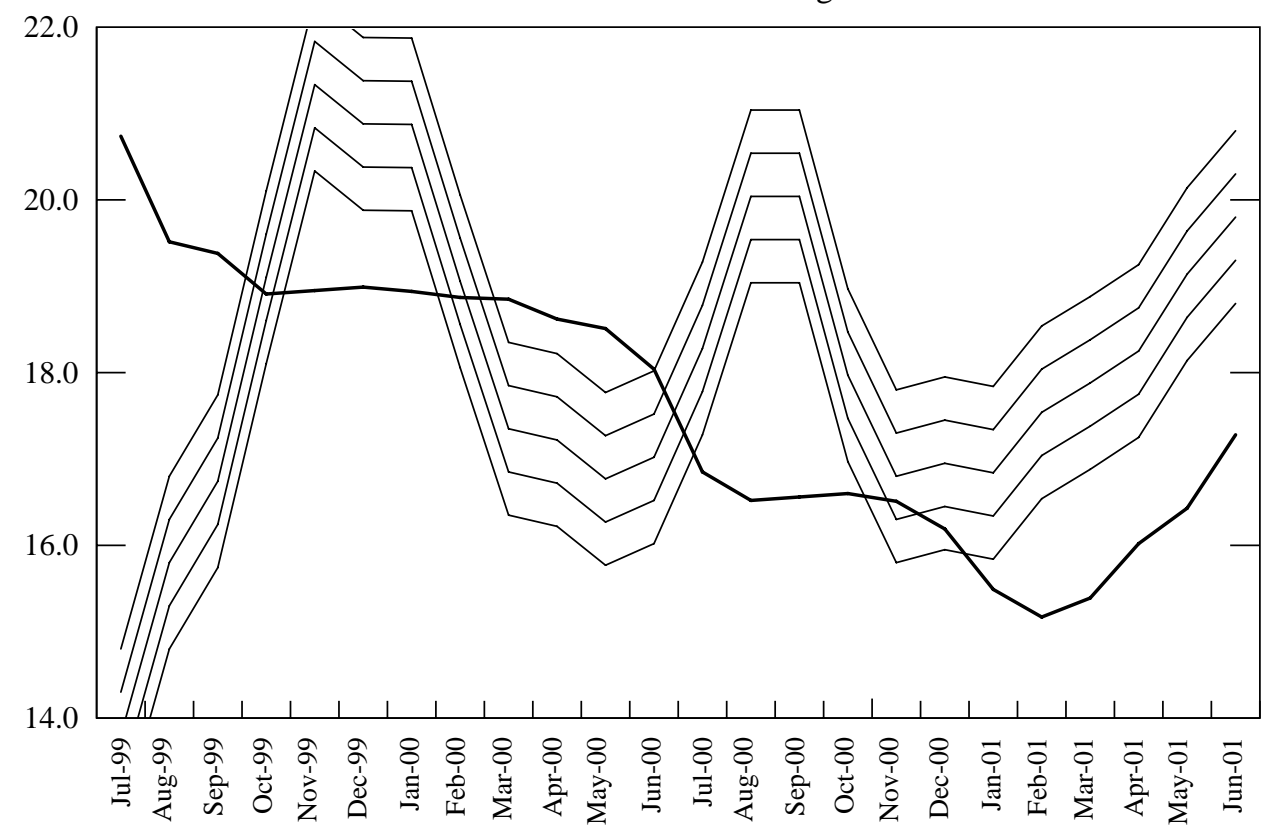

Source: BCB and authors' estimates. 
The second period runs from October 1999 to January-February 2000, when inflation had already picked up significantly, peaking in December 1999. During that period, the BCB basically "remained put," and, in particular, it did not raise the SELIC rate as would have been suggested by a simple Taylor rule. The increase suggested by a simple Taylor rule would have been particularly large without interest smoothing (Figure 2), whereas with interest smoothing (Figure 3), and depending on the value that is used for the equilibrium real interest rate $(\bar{r})$, the suggested increase would not necessarily have needed to be large. It is clear that, although in the last quarter of 1999 inflation was higher than expected, this was perceived as transitory by the Brazilian authorities. This view was also supported by market surveys, which continued to show that year 2000 inflation was expected to be significantly below 1999 inflation. As a result, the actual SELIC rate was kept slightly below the rate suggested by a simple Taylor rule without expectational variables.

A third period runs from about February 2000 to June 2000, when inflation continued on a downward trend and remained in line with the inflation target. The BCB acted cautiously during this period, with the actual SELIC rate held basically constant at 18.5 percent until June 2000, also in light of new external uncertainties (including, for example, increases in oil prices and stock market volatility), and some domestic uncertainties relating to pending Supreme Court decisions (concerning the revaluation of some savings accounts that had been underindexed for inflation in the late 1980s and early 1990s). Due to the reduction in actual inflation, the actual SELIC rate remained, in general slightly above the bands of our simple Taylor rule, as shown in Figures 2 and 3.

A fourth period runs from mid-2000 to about September 2000, when, following the positive inflation surprises during the first half of 2000 , the BCB reduced the SELIC rate by 100 basis points in June 2000, then by a further 50 basis points in early July, and again by another 50 basis points later in July. As a result, in a 30-day period, the short-term interest rate was lowered by 200 basis points to 16.5 percent. Interestingly, just as the BCB lowered the SELIC rate during June and July of 2000, the simple Taylor rule would have suggested increasing interest rates. This largely reflected an unexpected negative agricultural supply shock that had pushed up food prices due to adverse weather conditions, and an increase in inflation due to the strong adjustment of government-managed prices in a single month (July 2000), which included price adjustments of oil derivatives, electricity, and telecommunication services. It also reflected the fact that the output gap was rapidly narrowing as average real GDP growth went from 0.8 percent in 1999 to 4.4 percent in 2000 . However, the BCB essentially read these developments as factors that would not call into question meeting the year's inflation target, and that could be addressed by holding back on further interest rate reductions. In essence, this interpretation was correct, as, during the last quarter of 2000, the Taylor band fell back to levels that had prevailed earlier in the year, as the July-August surge in food prices was winding down. During this period, the actual SELIC rate remained broadly within or just below the Taylor bands shown in Figures 2 and 3. 
Figure 3. Brazil: Taylor Rules with Current Inflation

3a. The SELIC and a Simple Taylor Rule $(\mathrm{a}=0.5, \mathrm{~b}=1.5)$ Interest Rate Smoothing (rho $=0.6)$

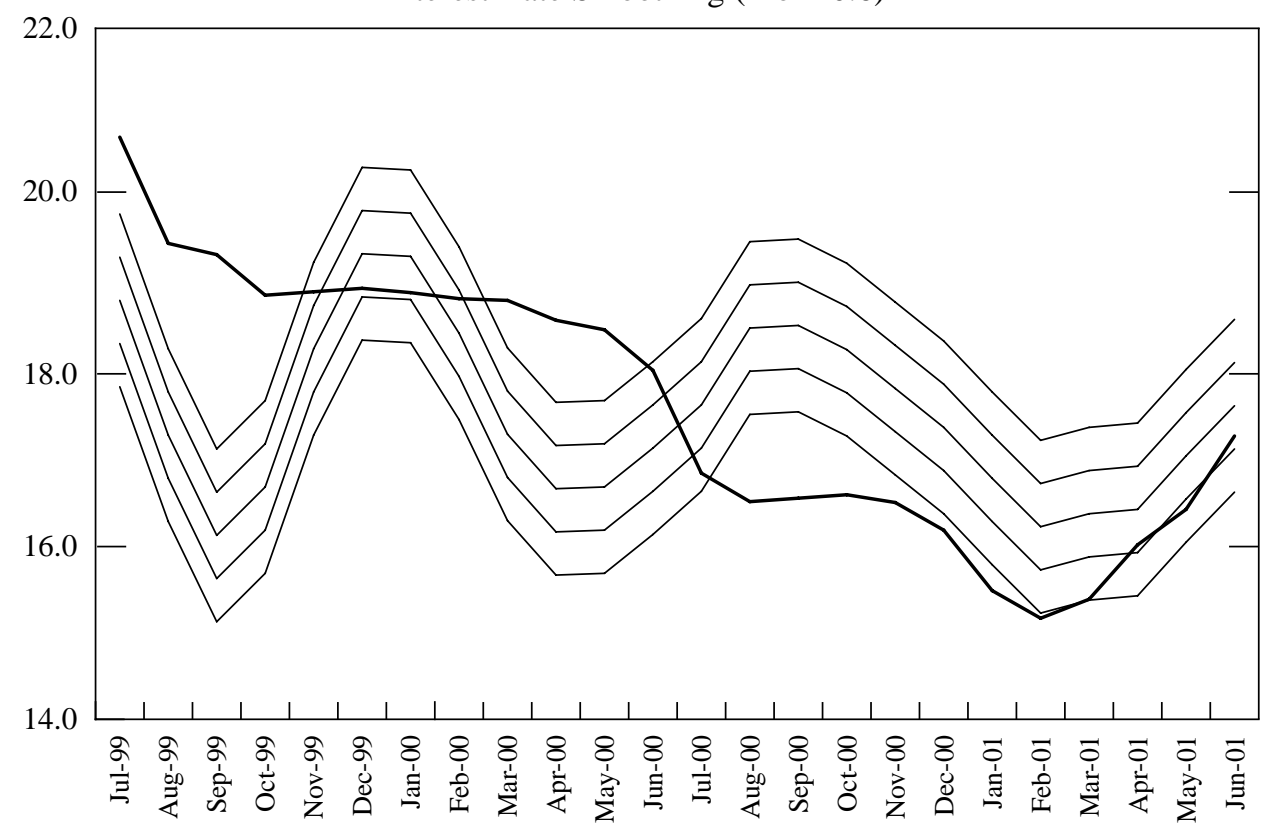

3b. The SELIC and a Simple Taylor Rule $(a=0, b=2)$ Interest Rate Smoothing $($ rho $=0.6)$

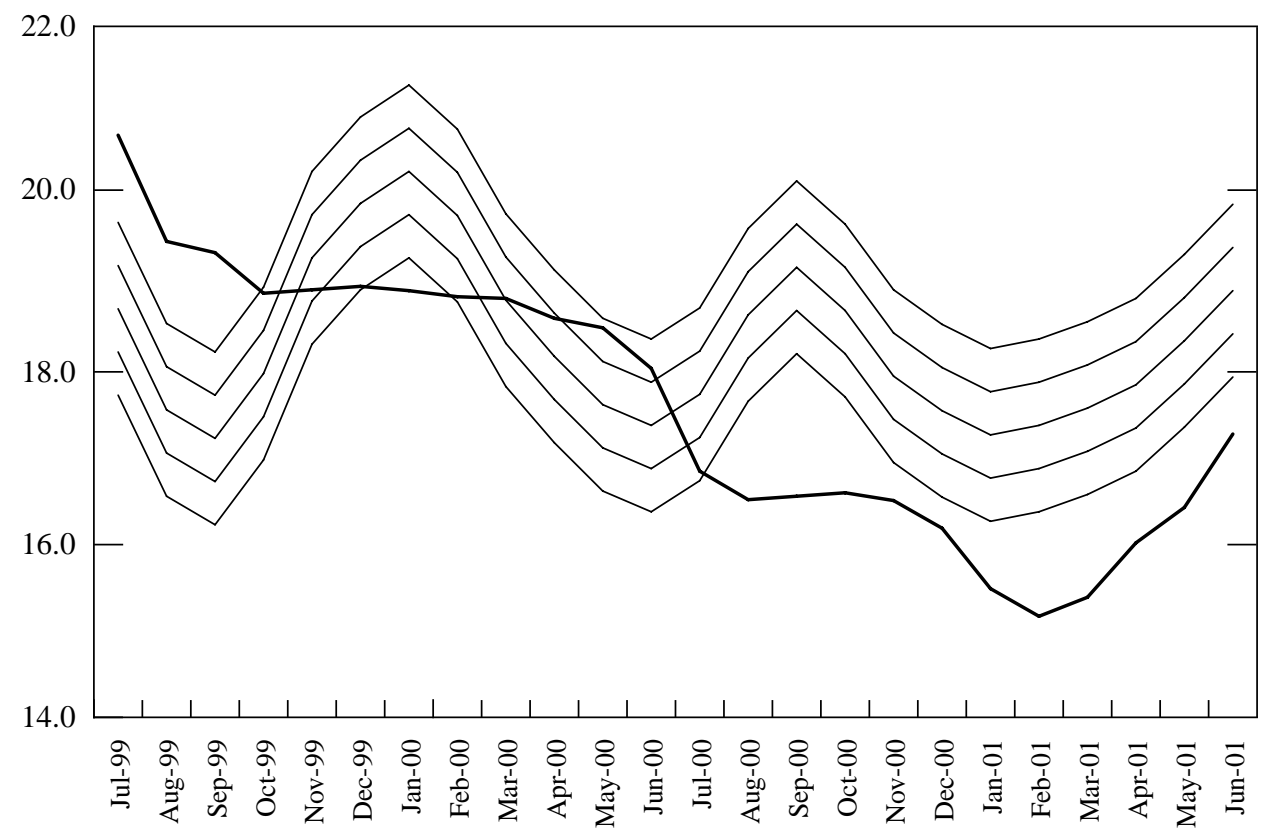

Source: BCB and authors' estimates. 
Starting in early 2001 and for the first half of the year, the simple Taylor bands signaled a need to increase interest rates, generally to levels above the ones maintained by the BCB, particularly when ignoring output considerations (which, in early 2001, showed an economy that was slowing down considerably in light of external factors and domestic energy rationing, thereby again opening an output gap). For example, a simple Taylor rule with no output considerations and no interest smoothing (Figure 2b), would, in an IMF program context, have triggered a consultation on the monetary policy stance in the first quarter of 2001, when the BCB had continued lowering the SELIC rate while the Taylor rule itself would have suggested an increase. With an actual 2001 inflation outcome of 6.7 percent, which was outside of the $+/-2$ percent tolerance interval around the year-end inflation target of 4 percent, a Taylor rule would have helped to trigger discussions already in the beginning of 2001, if not earlier, when, arguably, the BCB reacted too slowly to the need to raise interest rates.

This simple exercise may be interpreted in different ways, depending on the intended use of the Taylor rule. Simple mechanistic rules are not useful in policymaking, a fact that is amply highlighted in the recent literature, including on the still rather new Brazilian experience. ${ }^{20}$ Policy decisions have to be made on the basis of more complex considerations, and rules and models can only be one input in these decisions. Monetary policy rules are even simpler than standard models used by central banks to gauge their own policies, and even these models are still considered "small-scale" 21 compared to potentially more complex ones.

At the same time, however, simple rules - even of the type just discussed-may provide a rough first evaluation of a policy stance. ${ }^{22}$ Simple Taylor rules may only be expected to perform satisfactorily in an environment where relatively low inflation has already been achieved, and where the overall macroeconomic environment is fairly stable (for example, continued tight fiscal polices, and a stable exchange rate). In a more unstable or uncertain environment, other variables should be included in the Taylor rule to make it more "realistic." Making monetary rules more realistic would not necessarily mean making them more complicated. In general, central banks do not only react to current levels of specific variables but also to their expected future levels - they are clearly forward looking. Since the different channels of transmission of monetary policy are known to operate with some lags, all central banks forecast the behavior of inflation in one way or another. These expectations or forecasts could be put to use in the Taylor rules.

Accordingly, in Figures 4 and 5 we employ again a simple Taylor rule but use market projections of inflation, as derived from the BCB's daily survey on market expectations. ${ }^{23}$ In these examples, the main elements remain qualitatively

\footnotetext{
${ }^{20}$ See, for example, Bogdanski, de Freitas, Goldfajn, and Tombini (2001).

${ }^{21}$ See Bogdanski, Tombini, and Werlang (2000) for the case of Brazil. Also see Rabanal and Schwartz (2001b) for a review of the inflation forecasting performance of the small-scale model used by the BCB.

${ }^{22}$ This is probably also one of the reasons why the U.S. Federal Reserve Bank of St. Louis, for example, has been publishing the results of simple Taylor rules and McCallum rules in its monthly economic reports. See the Federal Reserve Bank of St. Louis (1999-2000).

${ }^{23}$ For the purpose of the Taylor rules, the expected inflation for a given month was generated by using the average expected inflation for that month, as shown in surveys carried out by the BCB in the month immediately preceding that month.
} 
unchanged from the previous analysis, also because expectations matched actual outcomes fairly closely. In general, there were again three periods where, if it had been employed in an IMF program context, a Taylor rule would have triggered an early consultation on the monetary policy stance. ${ }^{24}$ First in late 1999 , when the expectations of a higher future pass-through from currency depreciation to inflation peaked together with actual inflation; second in mid-2000, when Brazil experienced, among others, an agricultural supply shock that again pushed up inflation expectations; and third in early 2001, when inflation expectations took off, also in light of the domestic energy crisis and the substantial weakening of the exchange rate, in part reflecting the lingering concerns about Argentina. While the first two eventually turned out to be more transitory elements that could be accommodated by the inflation target without necessarily changing the policy stance, the latter had a more lasting impact, and eventually required the BCB to tighten its policy stance, albeit too late to keep the 2001 inflation outturn within the target range. A priori, however, each of these events would reasonably have been a good occasion to review the monetary policy stance in an IMF program context, and a Taylor rule could have been used as one option for triggering such consultations.

\section{Concluding Remarks}

In IMF programs, conditionality links the achievement of a set of policy objectives to continued access to Fund resources. Conditionality provides a yardstick for evaluating whether the policies that are being carried out are moving the country toward the achievement of stated policy objectives, in particular a sustainable external balance. By doing so, conditionality also safeguards the temporary use of the IMF's resources. Traditionally, program conditionality in the monetary area has relied on two performance criteria: a ceiling on the central bank's NDA and a floor on its NIR. The primary focus of this approach has always been a program's external viability, rather than inflation. The main role of the NIR floor is to indicate whether an IMF program is likely to achieve its external objective, while the ceiling on NDA seeks to ensure that this objective is not jeopardized by excessive credit expansion or by sterilized intervention-that is, by compensating unprogrammed NIR losses through additional credit creation. The framework assumes that the demand for base money matters from a macroeconomic perspective, and that it is stable and predictable.

As argued in this paper, in program countries that carry out their monetary policies on the basis of explicit inflation targets, it would seem helpful to adapt traditional monetary conditionality to take into account the specific features of inflation targeting. This would help to improve the correspondence between the monetary objectives of the central bank and the targets of the IMF-supported adjustment program, and the instruments that are used to achieve these targets and objectives. By the same token, it would also facilitate communication of central bank policies to the markets.

\footnotetext{
${ }^{24}$ See, for example, Figure $4 b$.
} 
Mario I. Blejer, Alfredo M. Leone, Pau Rabanal, and Gerd Schwartz

Figure 4. Brazil: Taylor Rules with Market Expectations of Inflation

4a. The SELIC and a Simple Taylor rule $(a=0.5, b=1.5)$

No Interest Rate Smoothing

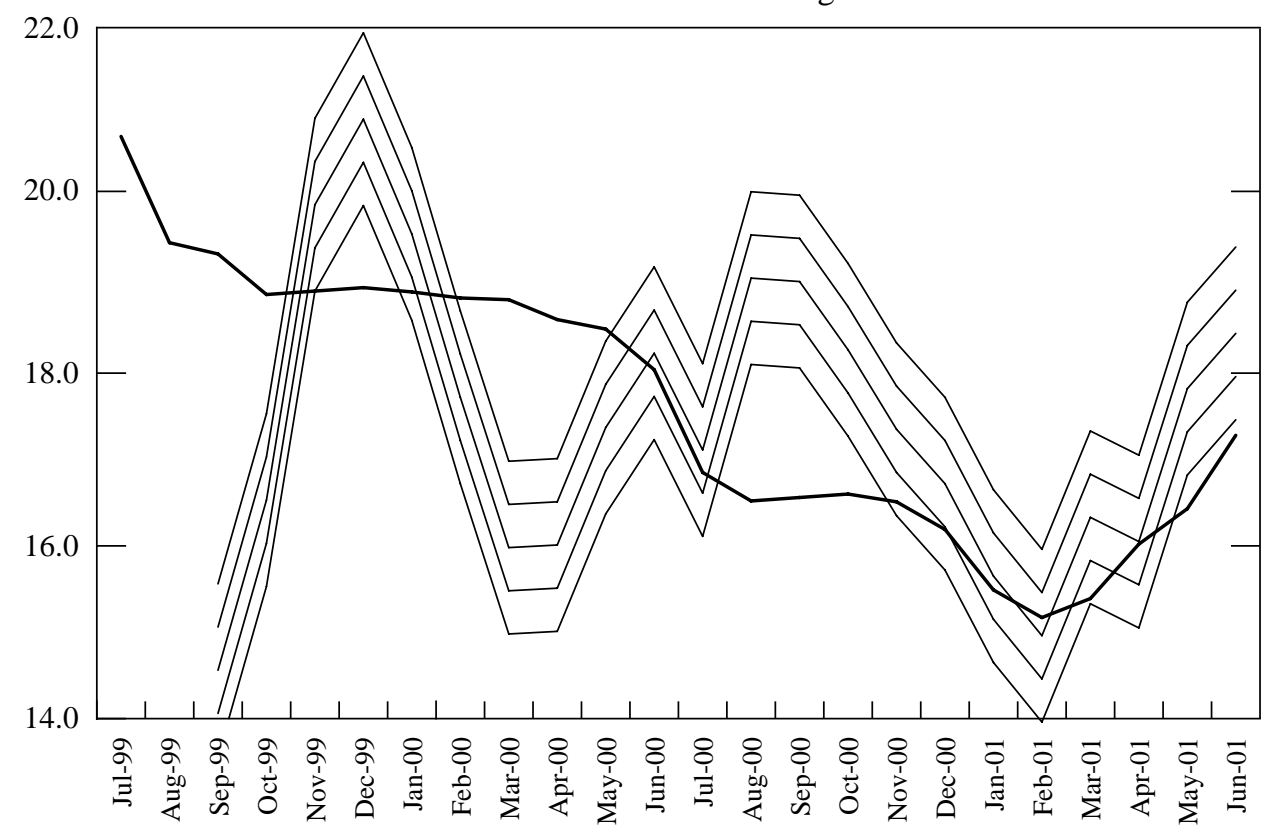

4b. The SELIC and a Simple Taylor Rule $(a=0, b=2)$

No Interest Rate Smoothing

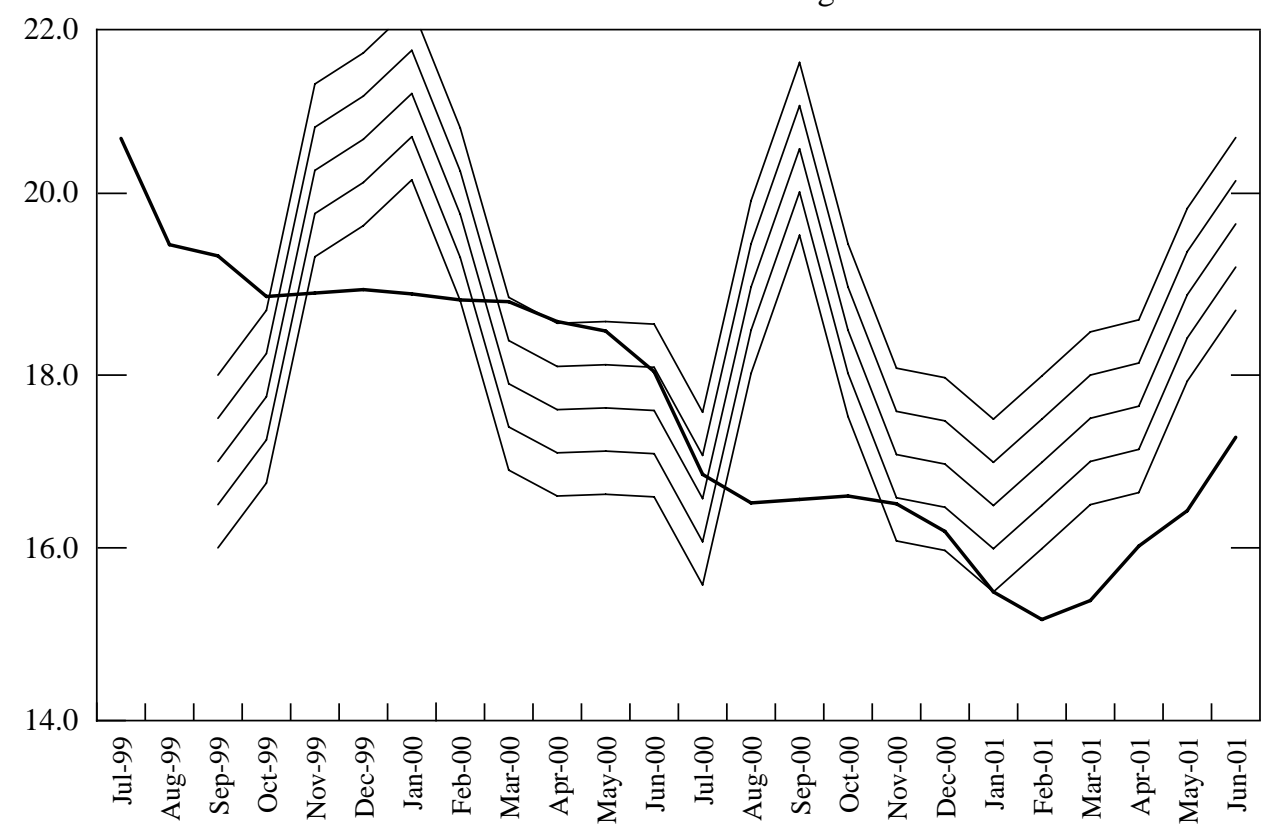

Source: BCB and authors' estimates. 
Clearly, as a first step, a program could include, as was the case in Brazil, the government's inflation target itself. Often, this may require specifying the target in some more detail than the official target. For example, most countries operate with annual inflation targets; however, as IMF programs are frequently monitored on a quarterly basis, additional quarterly inflation objectives may have to be added. Furthermore, there needs to be a mechanism for consultations that allows for program reviews to take place if inflation goes off track. This, in turn, would require establishing parameters around the targeted inflation rate that would trigger such reviews. In the case of Brazil it was decided to establish consultation bands around the central target, where, depending on the size of the deviation from the target, consultations with either IMF staff or its Executive Board would be triggered.

A potential drawback of monitoring a program on the basis of inflation outcomes-for example, on the basis of the actual 12-month rate of inflation visà-vis the target 12-month rate of inflation-is that this is largely backward looking; that is, the inflation outcome itself offers no guidance as to the appropriateness of the stance of monetary policies. Hence, inflation targets in the context of an IMF program work much in the same way in which they are used by the government: they are a parameter that helps to carry out an ex post analysis of central bank policies. However, to be able to say something about the appropriateness of the current monetary policy stance, it is not enough to look at actual inflation. This raises the question whether there are additional options for strengthening monetary conditionality under inflation targeting in the context of an IMF program. ${ }^{25}$ This could be achieved either by regular frequent consultations or by a forward-looking trigger mechanism for consultations between the country authorities and the IMF.

One option that has been explored in this paper, and on which further analysis would be desirable, is to consider simple monetary policy rules, such as Taylor rules or McCallum rules, as a potential trigger mechanism for such consultations. While simple policy rules would not be a useful device for policymaking, they do provide a rough first evaluation of a policy stance. To illustrate the point, we tested various simple Taylor rules, using the experience of Brazil in its first two years under inflation targeting as an example. The results of the exercise suggest that simple mechanical rules may indeed provide a rough initial yardstick on the appropriate level of interest rates, particularly in an environment where relatively low inflation has already been achieved, and where the overall macroeconomic environment is fairly stable (for example, continued tight fiscal polices, and a stable exchange rate).

To strengthen conditionality, and, in particular, to help monitor the stance of monetary policies vis-à-vis a government's inflation target, Taylor rules or other rules that provide for a rough evaluation of central bank policies are an area that could usefully be explored further. In general, to be useful in an IMF program context, the rules should be kept simple, and forward looking, in the sense that they should include inflation expectations.

\footnotetext{
${ }^{25}$ Knight (1999) also provides suggestions on IMF conditionality in the context of inflation targeting.
} 
Mario I. Blejer, Alfredo M. Leone, Pau Rabanal, and Gerd Schwartz

Figure 5. Brazil: Taylor Rules with Market Expectations of Inflation

5a. The SELIC and a Simple Taylor Rule $(\mathrm{a}=0.5, \mathrm{~b}=1.5)$

Interest Rate Smoothing (rho $=0.6)$

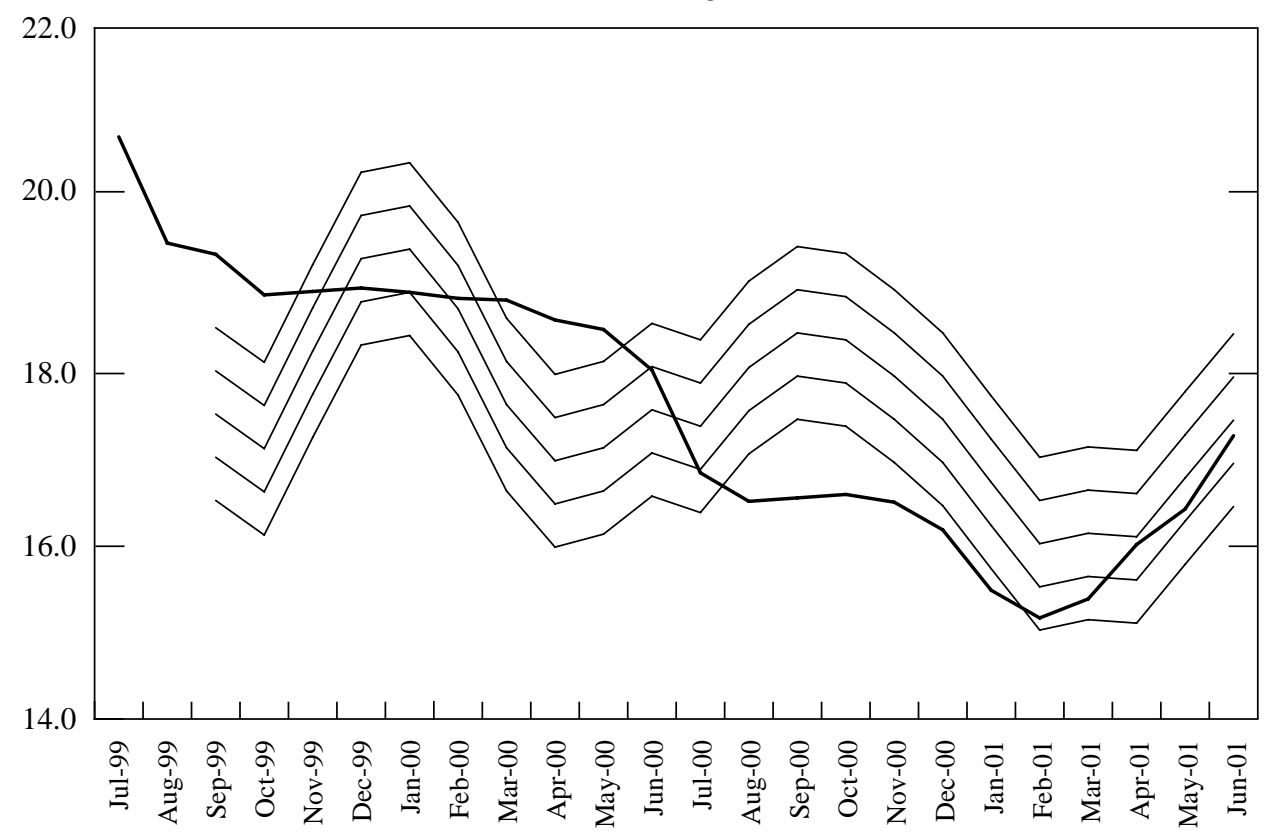

5b. The SELIC and a Simple Taylor Rule $(\mathrm{a}=0, \mathrm{~b}=2)$ Interest Rate Smoothing (rho $=0.6)$

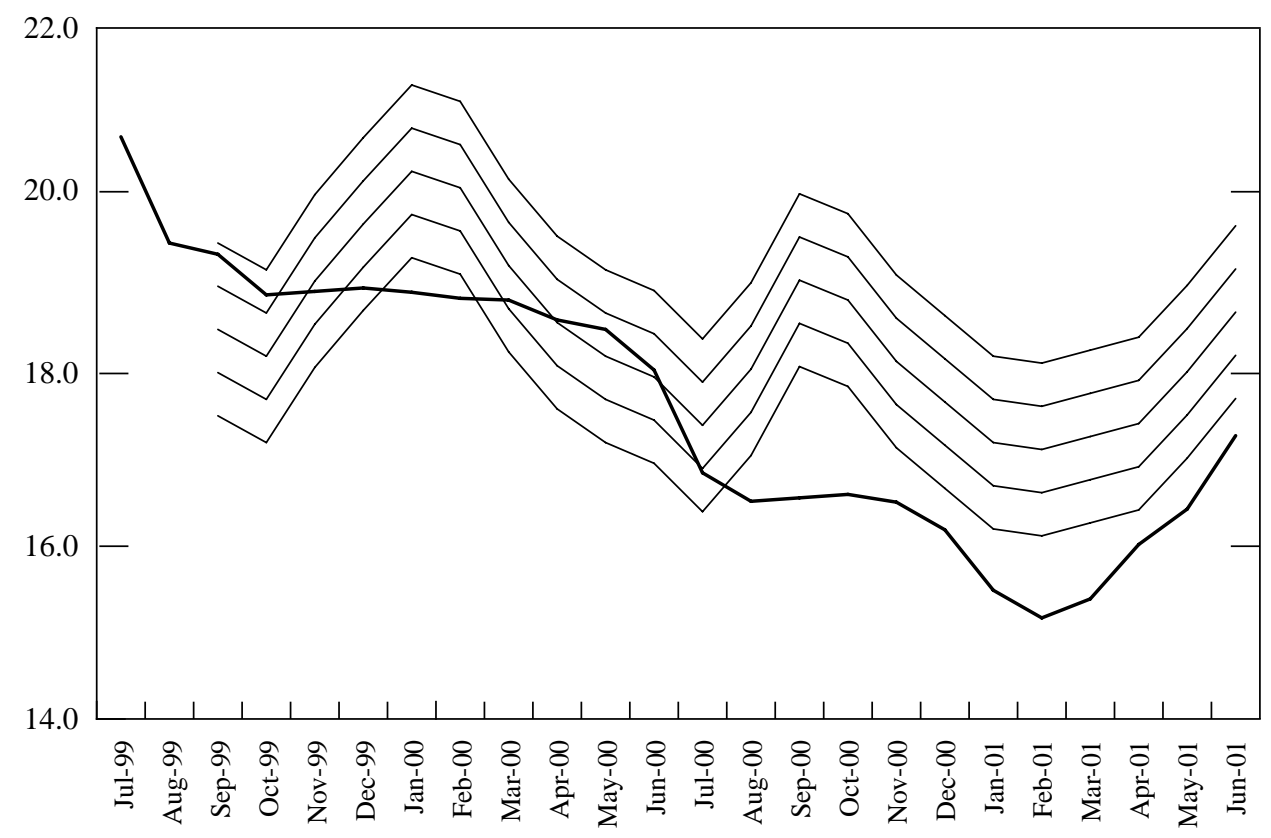

Source: BCB and authors' estimates. 


\section{APPENDIX}

\section{Taylor Rule Exercise for Brazil}

We use a simple Taylor rule for Brazil during 1999-2001 to compare actual policy outcomes with rule-based policy prescriptions. Using monthly data, the rule we use takes the standard form, with $r_{t}=\rho r_{t-1}+(1-\rho) \cdot\left[r^{*}+\alpha y_{t}+\beta\left(\pi_{t}-\pi_{t}^{*}\right)\right]$ and $r^{*}=\bar{r}=\pi_{t}^{*}$, where $r_{t}$ is the annualized overnight interest rate (SELIC) in period $t$; $\rho$ is the interest smoothing parameter with $0 \leq$ $\rho \leq 1 ; y_{t}$ is the output gap in period $t ; \pi_{t}$ is the 12 -month inflation rate in period $t ; \pi_{t}^{*}$ is the inflation target applicable to period $t ; r^{*}$ is the equilibrium nominal interest rate; and $\bar{r}$ is the equilibrium real interest rate. Parameters $\alpha$ and $\beta$ are the parameters of the Taylor rule, where, for simplicity, we choose those suggested in Taylor's original formulation with $\alpha$ equal to either 0 or 0.5 , depending on whether or not output considerations can be assumed to be part of the central bank's objective function, and $\beta$ being either 2 or 1.5 , accordingly.

In general, we use monthly end-of-period data for the SELIC rate and the other variables in the model. The output gap was first estimated by fitting a linear trend on the natural logarithm of monthly GDP, as estimated by the BCB. This yielded a relatively low potential real output growth, and we consequently used values in the range of 3-4 percent as being more realistic assumptions. The value of the equilibrium real interest rate was initially assumed to be 12.0 percent, but we then used values in the 10.5 percent to 12.5 percent range to generate the Taylor rule bands.

The inflation target for each month is a linear extrapolation of the quarterly targets for December 1999 to June 2001 that were used under the IMF program. For the period before December 1999, when inflation was still low, we used the lower band of the target range to derive the Taylor rule and then linearly increased it to reach 8 percent (the central target) in December 1999. Hence, for July 1999, we assume that the BCB did set its inflation target in the lower limit of its annual band for 1999 (6 percent), and that it increased this linearly to reach the inflation target of 8 percent in December 1999. However, using the December 1999 target for the period leading up to December 1999 did not change the outcomes qualitatively. Expected inflation for a given month (used in Figures 4 and 5) is the inflation expectation for the month at the beginning of the month, calculated as the average market expectation according to the BCB survey; other definitions of inflation expectations did not alter the results significantly.

We consider four policy rules: the original Taylor rule (with $\alpha=0.5$ and $\beta=1.5$ ), a more aggressive rule that only targets inflation $(\alpha=0, \beta=2)$, and for both rules we consider the case of no interest rate smoothing $(\rho=0)$ and with interest rate smoothing $(\rho=0.6)$. Choosing $\rho=$ 0.6 would seem to strike a balance between having a fairly high degree of interest rate smoothing and letting the effect "die out" after only a few periods.

\section{REFERENCES}

Banco Central do Brasil (1999-2000), Relatório de Inflação (various issues since June 1999).

Blejer, Mario I., Alain Ize, Alfredo M. Leone, and Sérgio R. C. Werlang, 2000, Inflation Targeting in Practice: Strategic and Operational Issues and Application to Emerging Market Economies (Washington: International Monetary Fund).

Bogdanski, Joel, Alexandre Antonio Tombini, and Sérgio Ribeiro da Costa Werlang, 2000, "Implementing Inflation Targeting in Brazil," Working Paper 1, July (Brasília: Banco Central do Brasil).

Bogdanski, Joel, Paulo Springer de Freitas, Ilan Goldfajn, and Alexandre Antonio Tombini, 2001, "Inflation Targeting in Brazil: Shocks, Backward-Looking Prices, and IMF Conditionality,” Working Paper 24, July (Brasília: Banco Central do Brasil). 
Fachada, Pedro, 2001, "Inflation Targeting in Brazil: Reviewing Two Years of Monetary Policy 1999/00,” Working Paper 25, August (Brasília: Banco Central do Brasil).

Federal Reserve Bank of St. Louis, 1999-2000, Monthly Trends (various issues).

Gold, Joseph, 1979, Conditionality, IMF Pamphlet Series 31 (Washington: International Monetary Fund).

Goldfajn, Ilan, and Sérgio R. C. Werlang, 2000, “The Pass-Through from Depreciation to Inflation: A Panel Study,” Working Paper 5, July (Brasília: Banco Central do Brasil).

Goodfriend, Marvin, and Jeffrey M. Lacker, 1999, "Limited Commitment and Central Bank Lending," Economic Quarterly, Vol. 85/4 (Fall), pp. 1-27 (Richmond, Virginia: Federal Reserve Bank of Richmond).

Guitián, Manuel, 1981, Fund Conditionality: Evolution of Principles and Practices. IMF Pamphlet Series 38 (Washington: International Monetary Fund).

Knight, Malcolm, 1999, "IMF Conditionality Under Inflation Targeting: Some Comments and Suggestions." Paper delivered at the IMF's Seminar on "Inflation Targeting and Fund Conditionality," October 28, 1999.

Kozicki, Sharon, 1999, “How Useful Are Taylor Rules for Monetary Policy?” Economic Review, second quarter of 1999, pp. 5-33 (Kansas City, Missouri: Federal Reserve Bank of Kansas City).

Rabanal, Pau, and Gerd Schwartz, 2001a, "Testing the Effectiveness of the Overnight Interest Rate as a Monetary Policy Instrument," Brazil: Selected Issues and Statistical Appendix, IMF Staff Country Report 01/10, pp. 114-35 (Washington: International Monetary Fund).

— 2001b, "Forecasting Inflation in Brazil: How Useful Are Time Series Techniques?" Brazil: Selected Issues and Statistical Appendix, IMF Staff Country Report, 01/10 (January), pp. 136-52 (Washington: International Monetary Fund).

Rudebusch, Glenn D., and Lars E.O. Svensson, 2002, "Eurosystem Monetary Targeting: Lessons from U.S. Data," European Economic Review, Vol. 46 (3), pp. 417-42.

Schaechter, Andrea, Mark R. Stone, and Mark Zelmer, 2000, Adopting Inflation Targeting: Practical Issues for Emerging Market Countries, IMF Occasional Paper 202 (Washington: International Monetary Fund).

Schwartz, Gerd, 1999, "Price Developments After the Floating of the Real: The First Six Months," Brazil: Selected Issues and Statistical Appendix, IMF Staff Country Report 99/97, pp. 7-35 (Washington: International Monetary Fund).

Svensson, Lars E.O., 2001, "What Is Wrong with Taylor Rules? Using Judgment in Monetary Policy Through Targeting Rules" (unpublished; Princeton and Stockholm: Princeton University and Stockholm University).

2002, "Inflation Targeting: Should It Be Modeled as an Instrument Rule or a Targeting Rule?" European Economic Review, Vol. 46 (4/5), pp. 771-80.

Taylor, John B., 1993, "Discretion Versus Policy Rules in Practice," Carnegie-Rochester Conference Series on Public Policy, Vol. 39, pp. 195-214. 